\title{
Exercise cardiac MR assessment of diastolic function
}

\author{
Christopher J Francois ${ }^{1 *}$, Omid Forouzan², Jared Warczytowa², Jacob A Macdonald ${ }^{3}$, Oliver Wieben³, \\ Naomi C Chesler ${ }^{2}$ \\ From 18th Annual SCMR Scientific Sessions \\ Nice, France. 4-7 February 2015
}

\section{Background}

Dyspnea with exertion is a common symptom in patients with left ventricular (LV) systolic and diastolic dysfunction. Assessing changes in systolic and diastolic hemodynamic parameters with exercise is necessary to thoroughly characterize these patients. Evaluation of changes in LV systolic function with exercise stress cardiac magnetic resonance (MR) has been demonstrated previously $[1,2]$. In this study we assessed the feasibility of assessing LV diastolic function with exercise cardiac magnetic resonance.

\section{Methods}

14 healthy subjects $(26.1 \pm 4.7$ years, 5 men/9 women $)$ were prospectively recruited according to an IRB-approved and HIPAA-compliant protocol. Supine, exercise cardiac MR was performed on a $1.5 \mathrm{~T}$ scanner (HDx and $450 \mathrm{~W}$, GE Healthcare, Waukesha, WI) using an MRI-compatible exercise device that enables exercise to be performed on the scanner table [3]. Transmitral inflow was assessed with 2D phase-contrast (PC) MRI (FOV $=370 \times 260 \mathrm{~mm}^{2}$; matrix $=256 \times 128 ; \mathrm{TR} / \mathrm{TE}=6.1 / 3.7 \mathrm{~ms} ; \mathrm{FA}=30^{\circ} ; \mathrm{ASSET}=2$; $\mathrm{VENC}=100 \mathrm{~cm} / \mathrm{s}$ ) acquired through the tips of the MV leaflets during diastole [4]. Exercise was performed at a constant workload $(36.1 \pm 7.5 \mathrm{~W})$ for $>3$ minutes. The flow measurements were acquired during a breath-hold immediately following cessation of exercise to minimize bulk motion artifacts. 2D PC MR images were analyzed with CV Flow (Version 3.3, Medis, Leiden, the Netherlands). Resting and exercise $\mathrm{E}$ and $\mathrm{A}$ velocities and $\mathrm{E} / \mathrm{A}$ ratios were recorded for each subject from the transmitral inflow-time curves. The paired Student's t-test was used to

Table 1 Summary of E- and A- velocities and E/A ratios at rest and following exercise.

\begin{tabular}{|c|c|c|c|c|}
\hline Subjects & Condition & $E(\mathrm{~cm} / \mathrm{s})$ & $\mathrm{A}(\mathrm{cm} / \mathrm{s})$ & $E / A$ \\
\hline \multirow[t]{2}{*}{ All $(\mathrm{N}=12)$} & Rest & $\begin{array}{c}82.0 \pm 18.7 \\
(61.6-134.4)\end{array}$ & $\begin{array}{l}53.0 \pm 17.3 \\
(34.2-95.6)\end{array}$ & $\begin{array}{r}1.63 \pm 0.43 \\
(1.00-2.35)\end{array}$ \\
\hline & Exercise & $\begin{array}{c}89.1 \pm 6.7 \\
(76.5-98.3) \\
P=0.25\end{array}$ & $\begin{array}{c}56.5 \pm 16.1 \\
(32.4-94.5) \\
P=0.63\end{array}$ & $\begin{array}{c}1.69 \pm 0.45 \\
(0.81-2.50) \\
P=0.73\end{array}$ \\
\hline \multirow[t]{2}{*}{$<20 \mathrm{bpm}$ increase in $\mathrm{HR}(\mathrm{N}=5)$} & Rest & $\begin{array}{c}92.7 \pm 24.7 \\
(68.4-134.4)\end{array}$ & $\begin{array}{l}55.9 \pm 17.7 \\
(42.1-83.6)\end{array}$ & $\begin{array}{r}1.74 \pm 0.50 \\
(1.00-2.12)\end{array}$ \\
\hline & Exercise & $\begin{array}{c}88.2 \pm 6.1 \\
(79.8-95.3) \\
P=0.74\end{array}$ & $\begin{array}{c}53.3 \pm 13.7 \\
(32.4-66.1) \\
P=0.75\end{array}$ & $\begin{array}{c}1.74 \pm 0.43 \\
(1.41-2.46) \\
P=0.99\end{array}$ \\
\hline \multirow[t]{2}{*}{ >20bpm increase in $\mathrm{HR}(\mathrm{N}=7)$} & Rest & $\begin{array}{l}73.6 \pm 11.8 \\
(61.6-95.6)\end{array}$ & $\begin{array}{l}51.1 \pm 20.7 \\
(34.2-95.6)\end{array}$ & $\begin{array}{r}1.56 \pm 0.45 \\
(1.00-2.35)\end{array}$ \\
\hline & Exericse & $\begin{array}{c}89.8 \pm 7.4 \\
(76.5-98.3) \\
P=0.01\end{array}$ & $\begin{array}{c}58.8 \pm 18.4 \\
(35.4-94.5) \\
P=0.50\end{array}$ & $\begin{array}{c}1.66 \pm 0.50 \\
(0.81-2.50) \\
P=0.71\end{array}$ \\
\hline
\end{tabular}

Values are reported as mean \pm standard deviation (range). There were trends of higher $\mathrm{E}$ - and $\mathrm{A}$ - velocities and $\mathrm{E} / \mathrm{A}$ ratios, but the increase in $\mathrm{E}$-velocity was only significant in subjects in whom heart rate increased $>20 \mathrm{bpm}$ relative to rest.

${ }^{1}$ Radiology, University of Wisconsin - Madison, Madison, WI, USA

Full list of author information is available at the end of the article

(c) 2015 Francois et al; licensee BioMed Central Ltd. This is an Open Access article distributed under the terms of the Creative Commons 

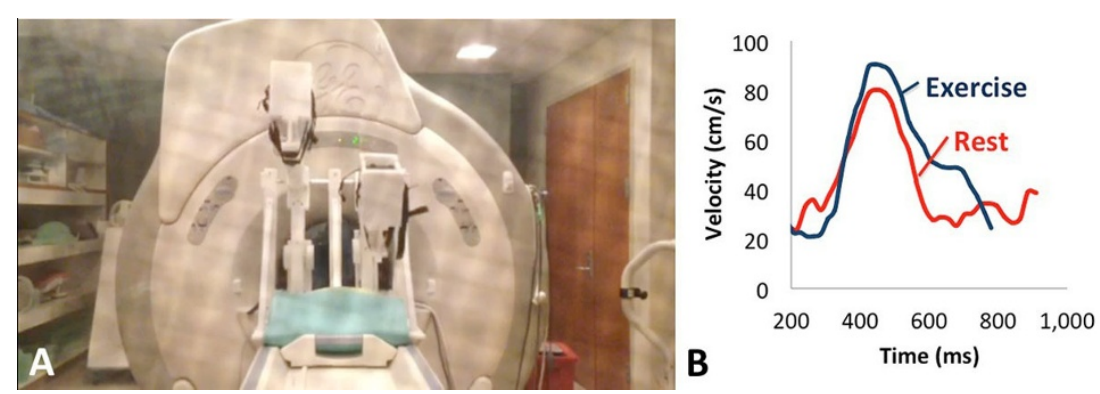

Figure 1 (A) MRl-exercise device with volunteer exercising in scanner. (B) Mitral valve flow-time curves at rest and during exercise in a healthy subject. The E/A ratios decreased and the E-wave deceleration times increased with exercise.

determine if differences between exercise and baseline were statistically significant.

\section{Results}

Exercise MV flow data was successfully acquired in $12 / 14$ subjects with heart rates increasing $25 \pm 10.6 \mathrm{bpm}$ relative to rest. In $2 / 14$ subjects, motion artifacts rendered the images unusable for analysis. $\mathrm{E}$ and $\mathrm{A}$ velocities and E/A ratios were higher than at rest, although the differences were not significant for the entire cohort (Table 1). In subjects that had an increase in heart rate $>20 \mathrm{bpm}$, E-velocities did increase significantly.

\section{Conclusions}

Quantification of exercise stress transmitral flow with MRI was feasible in the majority of healthy subjects, enabling the evaluation of exercise-induced changes in diastolic function. The findings of higher $\mathrm{E}$ and $\mathrm{A}$ indices is concordant with previously published data using exercise-stress echocardiography $[5,6]$.

\section{Funding}

NIH R01HL105598.

\section{Authors' details}

${ }^{1}$ Radiology, University of Wisconsin - Madison, Madison, WI, USA. ${ }^{2}$ Biomedical Engineering, University of Wisconsin - Madison, Madison, WI, USA. ${ }^{3}$ Medical Physics, University of Wisconsin - Madison, Madison, WI, USA.

Published: 3 February 2015

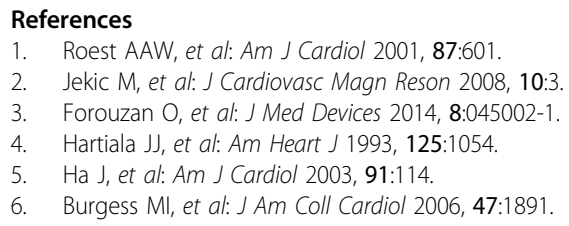

1. Roest AAW, et al: Am J Cardiol 2001, 87:601.

2. Jekic M, et al: J Cardiovasc Magn Reson 2008, 10:3.

3. Forouzan O, et al: J Med Devices 2014, 8:045002-1.

4. Hartiala JJ, et al: Am Heart J 1993, 125:1054.

5. Ha J, et al: Am J Cardiol 2003, 91:114.

6. Burgess Ml, et al: J Am Coll Cardiol 2006, 47:1891.

doi:10.1186/1532-429X-17-S1-P26

Cite this article as: Francois et al.: Exercise cardiac MR assessment of diastolic function. Journal of Cardiovascular Magnetic Resonance 201517 (Suppl 1):P26.

\section{Submit your next manuscript to BioMed Central} and take full advantage of:

- Convenient online submission

- Thorough peer review

- No space constraints or color figure charges

- Immediate publication on acceptance

- Inclusion in PubMed, CAS, Scopus and Google Scholar

- Research which is freely available for redistribution 